\title{
Conserved retinoblastoma protein-binding motif in human cytomegalovirus UL97 kinase minimally impacts viral replication but affects susceptibility to maribavir

\author{
Rachel B Gill ${ }^{\dagger 1,3}$, Samuel L Frederick ${ }^{\dagger 1}$, Caroll B Hartline ${ }^{1}$, Sunwen Chou ${ }^{2}$ \\ and Mark N Prichard*1
}

Address: ${ }^{1}$ Department of Pediatrics, University of Alabama School of Medicine, Birmingham, AL, USA, ${ }^{2}$ Medical and Research Services, VA Medical Center and Oregon Health and Science University, Portland, OR, USA and ${ }^{3}$ Department of Cell Biology, University of Alabama School of Medicine, Birmingham, AL, USA

Email: Rachel B Gill - rbgill@uab.edu; Samuel L Frederick - sfrederick@peds.uab.edu; Caroll B Hartline - chartline@peds.uab.edu; Sunwen Chou - chous@ohsu.edu; Mark N Prichard* - mprichard@peds.uab.edu

* Corresponding author †Equal contributors

\section{Published: 21 January 2009}

Virology Journal 2009, 6:9 doi:10.1186/1743-422X-6-9

This article is available from: http://www.virologyj.com/content/6/I/9

(c) 2009 Gill et al; licensee BioMed Central Ltd.

This is an Open Access article distributed under the terms of the Creative Commons Attribution License (http://creativecommons.org/licenses/by/2.0), which permits unrestricted use, distribution, and reproduction in any medium, provided the original work is properly cited.
Received: 29 December 2008

Accepted: 21 January 2009

\begin{abstract}
The UL97 kinase has been shown to phosphorylate and inactivate the retinoblastoma protein (Rb) and has three consensus Rb-binding motifs that might contribute to this activity. Recombinant viruses containing mutations in the Rb-binding motifs generally replicated well in human foreskin fibroblasts with only a slight delay in replication kinetics. Their susceptibility to the specific UL97 kinase inhibitor, maribavir, was also examined. Mutation of the amino terminal motif, which is involved in the inactivation of $\mathrm{Rb}$, also renders the virus hypersensitive to the drug and suggests that the motif may play a role in its mechanism of action.
\end{abstract}

\section{Findings}

Human cytomegalovirus (HCMV) is a ubiquitous virus that can be problematic in immunocompromised populations, including individuals with AIDS or recipients of allograft transplants. It is the most common congenital infection in the United States [1] and sequela include permanent neurological deficits, including hearing loss $[2,3]$. Ganciclovir (GCV), foscarnet and cidofovir (CDV) have all been approved for the treatment of HCMV infection, but each drug is associated with dose-limiting toxicities [4]. The benzimidazole L-riboside maribavir (MBV) is currently in Phase III clinical trials for the treatment of HCMV infections and inhibits viral replication by a distinct mechanism involving the direct inhibition of UL97 kinase activity [4-7]. While this drug clearly inhibits the enzymatic activity of the UL97 kinase in infected cells, the con- sequences of its inhibition are complex and incompletely understood as the kinase affects many cellular and viral processes.

The UL97 serine/threonine kinase is expressed early in infection and is found within the tegument of infectious virions $[8,9]$. Although the kinase is not required for viral replication, null mutants exhibit severe replication deficits [10], which is consistent with the inhibitory effects of MBV [5]. This enzyme has been shown to phosphorylate viral proteins including itself, ppUL44 and pp65 [11-13], as well as the large subunit of RNA polymerase II, eukaryotic elongation factor 1delta, P32 and lamins A/C [14-16]. The tumor suppressor retinoblastoma (Rb) has also been shown to be hyperphosphorylated in cells infected with HCMV [17], and this phosphorylation is dependent on 
UL97 kinase activity [18]. This report also showed that mutations in either the essential lysine (K355) or the conserved LxCxE Rb-binding motif in the amino terminus of pUL97 reduced the inactivation of $\mathrm{Rb}$ [18]. A separate study showed that the kinase phosphorylated Rb directly and did not require other proteins [19]. This activity is intriguing since $\mathrm{Rb}$ is also targeted by many viruses, including human papilloma virus, simian virus 40 , and adenovirus [20]. However, the interaction seems to be finely-tuned between HCMV and the cell and does not appear to result in an oncogenic phenotype exhibited by other viruses which target $\mathrm{Rb}$.

$\mathrm{Rb}$ belongs to the family of pocket proteins which prevent the progression of the cell through the $G_{1} / S$ checkpoint by binding to and suppressing the function of the transcription factor E2F; hyperphosphorylation of Rb causes it to release E2F which activates key steps in the cell cycle [21]. The inactivation of $\mathrm{Rb}$ by the kinase is presumed to modify cell checkpoint protein expression and induce the expression of cellular proteins required for viral infection, but its impact on viral replication has not been established. The UL97 gene product contains three consensus binding sequences for $\mathrm{Rb}[18,19]$; disruption of the essential lysine or the amino terminal Rb-binding motif (LxCxE) reduces the Rb phosphorylation seen in HCMV wild type (wt) inoculated cells [18]. Therefore, we hypothesized that viruses with disrupted Rb-binding sites in the UL97 kinase might have an impaired replication phenotype or altered susceptibility to antiviral drugs.

Recombinant viruses were engineered with point mutations in the UL97 open reading frame (ORF) and their construction was reported previously [18]. RC314 is a kinase-null virus with a K355M mutation. Recombinants RC295, RC312, and RC316 contain amino acid substitutions C151G (LxCxE), C428G (LxCxD) and C693G (IxCxE), respectively, that disrupt individual putative $\mathrm{Rb}-$ binding elements in the amino acid sequence of UL97. Another virus was constructed that contains both the C151G and the C428G mutations (RC323). Replication kinetics of each of these viruses were evaluated in low MOI infections of stationary HFF cells in the presence of $2 \%$ FBS. Disruption of the essential kinase motif in the UL97 ORF with a K355M mutation severely impacted the replication of the virus and was indistinguishable from that of RC $\Delta 97$ [Figure 1A]. This confirmed that the absence of kinase activity was responsible for the replication deficiency in the deletion mutant [10], and is consistent with results published previously [18]. Disruption of individual $\mathrm{Rb}$ binding motifs had minimal impact on virus replication in a 14-day time course [Figure 1B]. Growth curves for RC312, RC295, RC316, and RC323 were similar to that of the wt virus (HB5), although there appeared to be a slight delay at 4 and 5 days post infec- tion, with RC295 having the lowest titers. This result was repeatable and was confirmed in a second independent experiment with these viruses (data not shown). The double-mutant virus (RC323) also exhibited a minor replication delay in a separate experiment [Figure 1C]. These data suggest that the mutation of these sites has a minimal effect on viral replication.

A second set of viruses was constructed that contained a secreted alkaline phosphatase (SEAP)-expression cassette at US6 (T2211) [22]. The LxCxE motif was disrupted with a C151 deletion (T3038) and pUL97 was truncated at codon 536 to yield a null mutant (T2266). Replication of these viruses was assessed in human embryonic lung (HEL) cells infected at an MOI of 0.01-0.03 PFU/cell, and SEAP supernatant activity was determined with a chemiluminescent substrate. No detectable differences were observed between the wt virus (T2211) and the UL97 $\Delta \mathrm{C} 151$ virus (T3038) [Figure 1D]. The UL97-truncated virus (T2266) replicated poorly and had growth characteristics similar to those of RC314, and confirmed that defects in kinase activity could be detected in these studies. Results from both experiments indicated that mutation of the LxCxE motif did not severely impact virus replication. The minor delay in virus replication was not apparent in the T3038 and is likely related to assay differences. We conclude that the disruption of each of the $\mathrm{Rb}$ binding motifs individually or of the two amino terminal motifs in tandem has only minor effects on viral replication in cell culture. However, we cannot exclude the possibility that the disruption of all three may impact growth or that replication may be more compromised in other systems.

The mutations also had the potential to impact the efficacy of MBV and GCV, so the susceptibility of the mutants was determined by standard plaque reduction assays [23]. MBV was obtained from the National Institute of Allergy and Infectious Diseases (NIAID), CDV was a gift from Gilead Sciences and GCV was obtained from University of Alabama, Birmingham Hospital Pharmacy. All of the viruses were equally susceptible to the CDV control and was expected since this nucleotide analog does not require initial phosphorylation by the UL97 kinase [Table 1]. The kinase null virus, RC314, exhibited reduced susceptibility to GCV and MBV and is similar to results reported previously for RC $\Delta 97$ [23]. None of the viruses with mutations in the $\mathrm{Rb}$ binding motifs exhibited significant differences in their sensitivity to GCV, and confirmed that the mutations did not impact the enzymatic activity of the kinase. Interestingly, the disruption of the amino terminal $\mathrm{LxCxE}$ motif in RC295 rendered it modestly hypersensitive to $\mathrm{MBV}$, which suggests that the Rb binding motif might be related to the mechanism of action of MBV. This is consistent with a previous report, which showed only this 

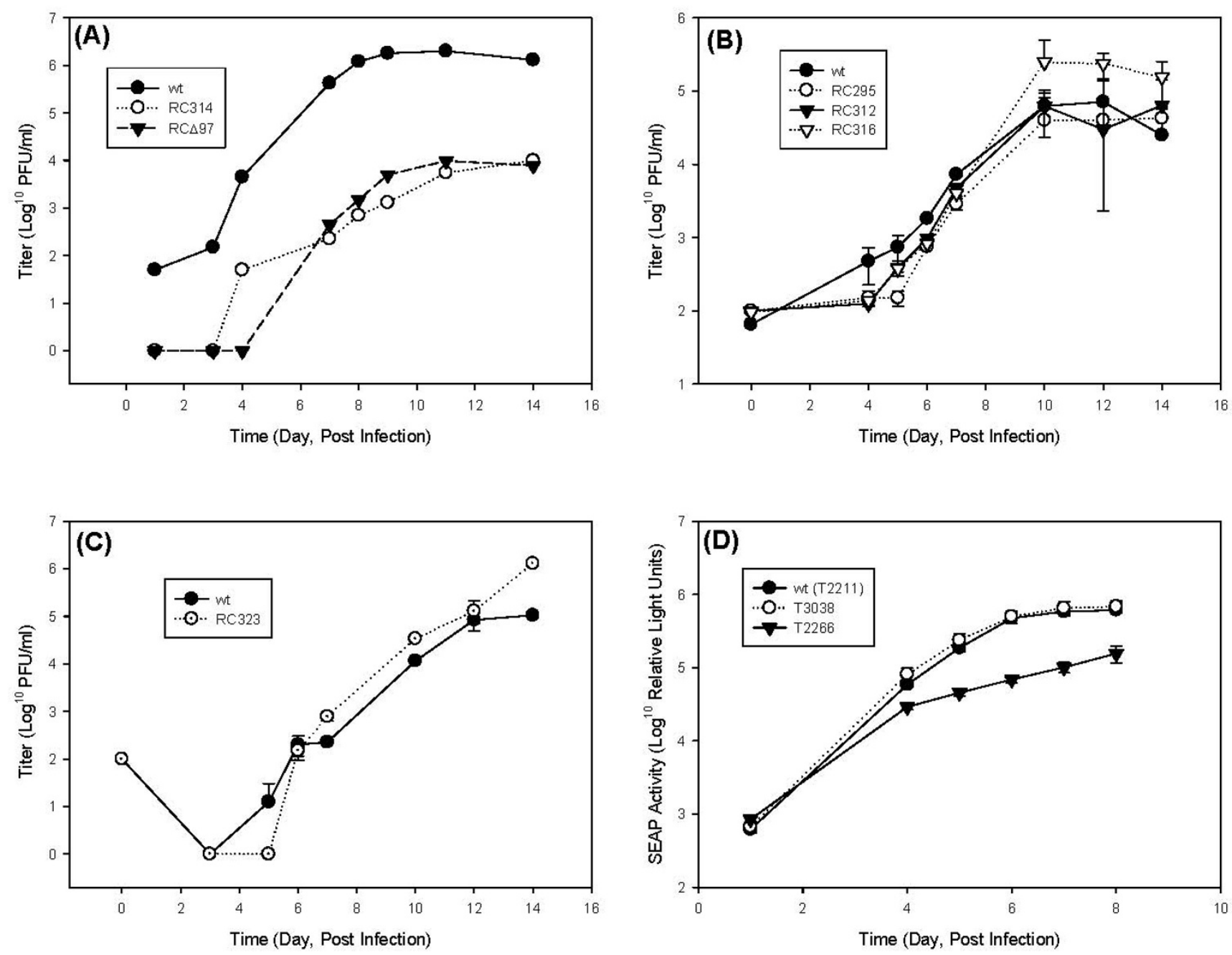

Figure I

Growth curves of HCMV recombinants with mutations in UL97. HFF cells were infected at an MOI of $0.0 \mathrm{I}$ PFU/cell and titers of the resulting progeny virus in cell lysates were determined at the indicated times. (A) Both a UL97-deleted virus (black triangles) and a null mutant with a K355M mutation (open circles) replicate poorly compared to the HB5 parent virus (black circles). (B) Replication kinetics of recombinant viruses with mutations in putative Rb-binding sites were determined and exhibit a slight delay in replication. Shown are the average titers from 2 replicate cultures with error bars representing the standard deviation values. RC295 (open circles) contains a mutation in the LxCxE motif, RC3 I 2 (black triangles) has a mutation in the LxCXD motif, RC3 16 (open triangles) carries a mutation in the IxCxE motif, and titers of the parent virus are shown as black circles. (C) RC323 (open circles) contains mutations in both the LxCxE and the LxCxD motifs and is shown with HB5 as a control (black circles). (D) Growth curves of SEAP-expressing HCMV recombinants with mutations in UL97 were examined separately; shown is the average SEAP activity of 5 replicates with the error bars representing the standard deviations. Replication of the wild-type virus with a SEAP-expression cassette (black circles) is similar to that of the recombinant virus with a deletion of codon I5I which disrupts the LxCxE motif (open circles), and both replicate much better than the virus with a truncation of the UL97 open reading frame (black triangles).

motif appeared to impact $\mathrm{Rb}$ phosphorylation [18]. It was not clear, however, why this mutation did not affect MBV susceptibility of the double mutant, but this effect was difficult to measure because of the assay-to-assay variability with this virus.

To confirm these data, the susceptibility of the SEAPreporter viruses was also evaluated against GCV and MBV using SEAP activity as a surrogate marker of viral replication. Data were obtained by infecting confluent HEL fibroblasts at an MOI of 0.01-0.03 PFU/cell and SEAP activity in the supernatant was determined 6 days following infection [24]. MBV sensitivity data are the average of 8 determinations from 3 independent experiments for the T3038 and T2211 viruses tested simultaneously; the GCV $\mathrm{EC}_{50}$ values are consistent with historical data and are 
Table I: UL97 recombinant sensitivity to Maribavir

\begin{tabular}{|c|c|c|c|c|c|}
\hline Virus & AA Mutation & Rb-binding Motif & $\mathrm{MBV}^{a}$ & CDV & GCV \\
\hline HB5 & wt & wt & $0.37 \pm 0.03$ & $0.15 \pm 0.05$ & $3.6 \pm 3$ \\
\hline $\mathrm{RC} 314$ & K355M & wt & $14 \pm 5$ & $0.1 \pm 0.07$ & $38 \pm 10$ \\
\hline $\mathrm{RC} 295$ & CI5IG & LxCxE & $0.22 \pm 0.08^{c}$ & $0.18 \pm 0.04$ & $2.8 \pm 0.9$ \\
\hline $\mathrm{RC} 312$ & C428G & $L x C x D$ & $0.39 \pm 0.2$ & $0.22 \pm 0.1$ & $4.2 \pm 2$ \\
\hline $\mathrm{RC} 316$ & C693G & IxCxE & $0.3 \pm 0.1$ & $0.18 \pm 0.1$ & $3.2 \pm 3$ \\
\hline $\mathrm{RC} 323$ & C428G/CI5IG & $\mathrm{LxCxD} / \mathrm{LxCxE}$ & $0.5 \pm 0.2$ & $0.08 \pm 0.05$ & $3.5 \pm 3$ \\
\hline$T 2211^{b}$ & wt & wt & $0.100 \pm 0.008$ & $0.23 \pm 0.01$ & $1.16 \pm 0.18$ \\
\hline T3038 & $\Delta \mathrm{CI} \mid 5 \mathrm{I}$ & $\mathrm{LxCxE}$ & $0.031 \pm 0.002^{c}$ & $0.27 \pm 0.01$ & $1.03 \pm 0.13$ \\
\hline
\end{tabular}

a. Values shown are the concentrations of drugs $(\mu \mathrm{M})$ that are sufficient to reduce viral replication by $50 \%\left(\mathrm{EC}_{50}\right)$ with standard deviation shown. Each value is the average of at least 3 experiments.

b Values were obtained using a surrogate assay from viruses containing a SEAP expression cassette at US6.

c. Values were reduced significantly from the isogenic control viruses as determined by the Student's T-test ( $P<0.05)$.

shown as the average of triplicate determinations. These data confirmed that the disruption of the amino terminal Rb-binding domain resulted in significantly increased sensitivity to MBV. While the $\mathrm{EC}_{50}$ values differ between the plaque reduction assays and the SEAP assays, both assays are consistent in that they both show that disruption of the amino terminal $\mathrm{Rb}$ binding motif results in increased susceptibility to MBV. These suggest that the mechanism of action of MBV may involve the $\mathrm{LxCxE} \mathrm{Rb}$ binding motif and is consistent with the idea that the prevention of $\mathrm{Rb}$ inactivation by MBV might be an important aspect of its mechanism of action.

Disruption of the central cysteines in the UL97 Rb-binding motifs does not result in a severe replication deficiency reminiscent of kinase null viruses, but rather results in a very modest delay in viral replication. This might suggest that the inactivation of $\mathrm{Rb}$ is not a crucial function in HFF or HEL cells and that it may be important only in vivo. Alternatively, it is possible that the motifs are redundant and all of them must be deleted to impact replicative ability of the virus. Nevertheless, the C151G mutation in the RC295 virus and the C151 deletion in the T3038 virus clearly conferred hypersensitivity to MBV when compared to their isogenic controls. While potential mechanisms for this are unclear, it indicates that mechanism of action of the drug is related to the function of the amino terminal Rb-binding motif at some level. Additional experiments will be required to assess the potential impact of double and triple mutants. Nonetheless, these findings offer insight into a new aspect of MBV activity and additional studies with the inhibitor together with genetic studies will help define the function of the kinase in viral infection.

\section{Abbreviations}

Rb: retinoblastoma protein; HCMV: human cytomegalovirus; GCV: ganciclovir; CDV: cidofovir; MBV: maribavir; SEAP: secreted alkaline phosphatise; MOI: multiplicity of infection; HEL: human embryonic lung fibroblasts;
NIAID: National Institute of Allergy and Infectious Diseases; ORF: Open reading frame; HFF: human foreskin fibroblasts; wt: wild type.

\section{Competing interests}

The authors declare that they have no competing interests.

\section{Authors' contributions}

RBG participated in virus production and data analysis and drafted the manuscript. SLF carried out virus production. CLH performed drug sensitivity studies and growth curve analyses. SC participated in construction and analyses of SEAP virus experiments. MNP participated in experimental design and implementation and assisted in drafting the manuscript. All authors read and approved the final manuscript.

\section{Acknowledgements}

We thank Gail Marousek for expert technical assistance. This work was supported by the Department of Veterans Affairs research funds and Public Health Service contract NOI-AI-30049 from NIAID, NIH, Bethesda, MD.

\section{References}

I. Cytomegalovirus (CMV) [http://www.cdc.gov/cmv/index.htm]

2. Boppana SB, Fowler KB, Pass RF, Rivera LB, Bradford RD, Lakeman FD, Britt WJ: Congenital cytomegalovirus infection: association between virus burden in infancy and hearing loss. J Pediatr 2005, I 46:817-823

3. Fowler KB, Boppana SB: Congenital cytomegalovirus (CMV) infection and hearing deficit. J Clin Virol 2006, 35:226-23I.

4. Biron KK: Antiviral drugs for cytomegalovirus diseases. Antiviral Res 2006, $71: 154-163$.

5. Biron KK, Harvey RJ, Chamberlain SC, Good SS, Smith AA 3rd, Davis MG, Talarico CL, Miller WH, Ferris R, Dornsife RE, et al.: Potent and selective inhibition of human cytomegalovirus replication by I 263W94, a benzimidazole L-riboside with a unique mode of action. Antimicrob Agents Chemother 2002, 46:2365-2372.

6. Chou S: Cytomegalovirus UL97 mutations in the era of ganciclovir and maribavir. Rev Med Virol 2008, 18:233-246.

7. Wang LH, Peck RW, Yin Y, Allanson J, Wiggs R, Wire MB: Phase I safety and pharmacokinetic trials of I 263W94, a novel oral anti-human cytomegalovirus agent, in healthy and human immunodeficiency virus-infected subjects. Antimicrob Agents Chemother 2003, 47: I334- I342.

8. Michel D, Pavic I, Zimmermann A, Haupt E, Wunderlich K, Heuschmid M, Mertens T: The UL97 gene product of human cytomegalovirus is an early-late protein with a nuclear local- 
ization but is not a nucleoside kinase. I Virol 1996, 70:6340-6346.

9. van Zeijl M, Fairhurst J, Baum EZ, Sun L, Jones TR: The human cytomegalovirus UL97 protein is phosphorylated and a component of virions. Virology 1997, 23 I:72-80.

10. Prichard MN, Gao N, Jairath S, Mulamba G, Krosky P, Coen DM, Parker BO, Pari GS: A recombinant human cytomegalovirus with a large deletion in UL97 has a severe replication deficiency. J Virol 1999, 73:5663-5670.

II. Baek MC, Krosky PM, He Z, Coen DM: Specific phosphorylation of exogenous protein and peptide substrates by the human cytomegalovirus UL97 protein kinase. Importance of the P+5 position. J Biol Chem 2002, 277:29593-29599.

12. Kamil JP, Coen DM: Human cytomegalovirus protein kinase UL97 forms a complex with the tegument phosphoprotein pp65. J Virol 2007, 8 I: I0659-10668.

13. Krosky PM, Baek MC, Jahng WJ, Barrera I, Harvey RJ, Biron KK, Coen DM, Sethna PB: The human cytomegalovirus UL44 protein is a substrate for the UL97 protein kinase. J Virol 2003, 77:7720-7727.

14. Baek MC, Krosky PM, Pearson A, Coen DM: Phosphorylation of the RNA polymerase II carboxyl-terminal domain in human cytomegalovirus-infected cells and in vitro by the viral UL97 protein kinase. Virology 2004, 324: 184-193.

15. Kawaguchi $Y$, Matsumura T, Roizman B, Hirai K: Cellular elongation factor I delta is modified in cells infected with representative alpha-, beta-, or gammaherpesviruses. J Virol 1999, 73:4456-4460

16. Marschall M, Marzi A, aus dem Siepen P, Jochmann R, Kalmer M, Auerochs $S$, Lischka $P$, Leis $M$, Stamminger T: Cellular $p 32$ recruits cytomegalovirus kinase pUL97 to redistribute the nuclear lamina. J Biol Chem 2005, 280:33357-33367.

17. Jault FM, Jault JM, Ruchti F, Fortunato EA, Clark C, Corbeil J, Richman DD, Spector DH: Cytomegalovirus infection induces high levels of cyclins, phosphorylated Rb, and p53, leading to cell cycle arrest. J Virol 1995, 69:6697-6704.

18. Prichard MN, Sztul E, Daily SL, Perry AL, Frederick SL, Gill RB, Hartline CB, Streblow DN, Varnum SM, Smith RD, Kern ER: Human cytomegalovirus UL97 kinase activity is required for the hyperphosphorylation of retinoblastoma protein and inhibits the formation of nuclear aggresomes. J Virol 2008, 82:5054-5067.

19. Hume AJ, Finkel JS, Kamil JP, Coen DM, Culbertson MR, Kalejta RF: Phosphorylation of retinoblastoma protein by viral protein with cyclin-dependent kinase function. Science 2008 320:797-799.

20. Felsani A, Mileo AM, Paggi MG: Retinoblastoma family proteins as key targets of the small DNA virus oncoproteins. Oncogene 2006, 25:5277-5285.

21. Sun A, Bagella L, Tutton S, Romano G, Giordano A: From G0 to S phase: a view of the roles played by the retinoblastoma $(\mathbf{R b})$ family members in the Rb-E2F pathway. J Cell Biochem 2007, 102: I 400-I 404

22. Chou S, Wechel LC, Marousek GI: Cytomegalovirus UL97 kinase mutations that confer maribavir resistance. J Infect Dis 2007 196:91-94

23. Williams SL, Hartline CB, Kushner NL, Harden EA, Bidanset DJ, Drach JC, Townsend LB, Underwood MR, Biron KK, Kern ER: In vitro activities of benzimidazole $D$ - and L-ribonucleosides against herpesviruses. Antimicrob Agents Chemother 2003, 47:2186-2192.

24. Chou S, Van Wechel LC, Lichy HM, Marousek GI: Phenotyping of cytomegalovirus drug resistance mutations by using recombinant viruses incorporating a reporter gene. Antimicrob Agents Chemother 2005, 49:2710-27I5. Publish with Biomed Central and every
scientist can read your work free of charge

"BioMed Central will be the most significant development for disseminating the results of biomedical research in our lifetime. "

Sir Paul Nurse, Cancer Research UK

Your research papers will be:

- available free of charge to the entire biomedical community

- peer reviewed and published immediately upon acceptance

- cited in PubMed and archived on PubMed Central

- yours - you keep the copyright

Submit your manuscript here:

http://www.biomedcentral.com/info/publishing_adv.asp
BioMedcentral 